\section{From the President}

The celebration of the 25th Anniversary of the foundation of EPS last September in Florence, the cradle of the Renaissance, helped remind us that the founding fathers were wise to root the Society in Europe's rich, multicoloured, cultural traditions. By having national physical societies involved along with individual members and various organizations as Associates, they succeeded in balancing the different interests of large and small societies, several disciplines, academia and industry, individuals, and larger communities. By securing a forum to exchange ideas and information, and by promoting cooperation and high-quality physics education, the Society, in spite of difficulties connected mainly with the shortage of finance and with the political separation of Europe, was able to play an important rôle in the development of physics.

Our surroundings have changed in the last 25 years. The most positive feature is the disappearance of the Iron Curtain and the end of the Cold War. Cooperation, one of the main driving forces for scientific development, has therefore become much easier for the whole of Europe. The negative changes are based on crisis-like financial difficulties and a strong anti-science feeling in all our countries. Physics is not excluded because science during the last few decades was dominated by physicists. The objective basis for this emphasis was the part played by physics in major discoveries. My deep belief is that science in general and physics in particular is going to remain, and to even increase in importance, as one of the main driving forces for economic development. It is, of course, difficult to forecast in detail what will happen in science in the 21st century. The discoveries of Copernicus, Einstein, Bohr, or Heisenberg could not be predicted and similar, unexpected discoveries in the future cannot be excluded. Some may be delayed by mistakes such as in the case of cold fusion, or shelved because of vital but short-sighted industrial interests. Nonetheless, both expected and unexpected discoveries will accelerate the development of science and open up new directions, fields and opportunities for future activity.

Since physics will remain one of the bases of technological and product development, relations between science and technology, between basic research and innovation or product development, must become closer than they are today. Basic scientific knowledge is needed more and more for innovation as can already be seen in, for example microelectronics, biotechnology and engineered materials; this tendency is expected to accelerate. However, the changes experienced in the development of modern research has resulted in permanently increasing costs. This led to the present situation where even the largest and wealthiest countries cannot afford the full spectrum of research; they face the need to make hard choices in setting priorities for their research projects and the fields of research they finance. Basic research is particularly exposed to these difficulties. The innovation process depends on much more than basic research since a large fraction of technological innovation is based, for instance, on simple solutions - on easily accessible information Innovation can therefore arise without the results of basic research so countries with

From the left, Norbert Kroo, the EPS President, with D.S. Langenberg, President of The American Physical Society, and $M$. Konuma, Past-President of The Physical Society of Japan, at the UNESCO Consultative Meeting (Paris, 24-25 June 1993). F. Mayor, UNESCO's Director-General, has followed up one of the meeting's recommendations by appointing a Physics Advisory Committee last December to "promote and develop collaboration in physics".

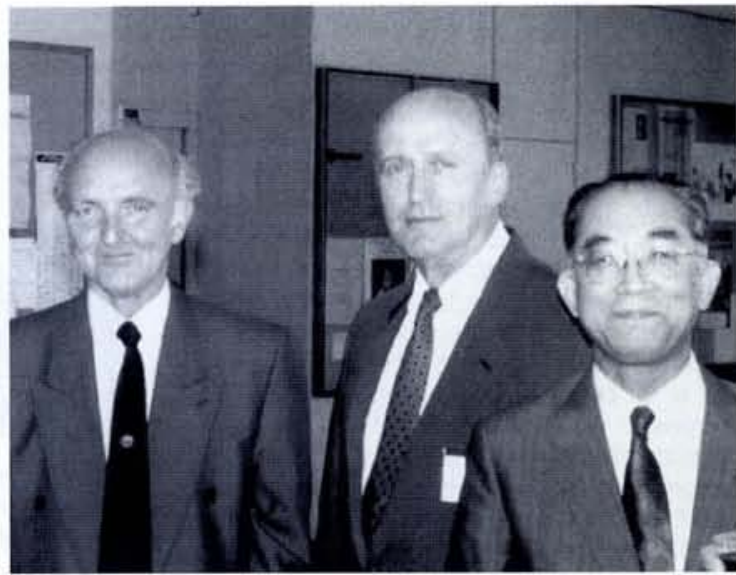

severe financial constraints are tempted to decrease the financing of this type of research. The tendency can be partly compensated for by concentrating on those aspects of physics which society at large acknowledges to be important. New materials, basic aspects of new technologies, research connected with the protection of the environment, clean energy sources, most interdisciplinary studies, and several other fields are accepted by the general public as representing "useful research".

Knowledge has never become obsolete as rapidly as today - a process which is expected to become even faster. This, however, does not apply to basic scientific knowledge, and in particular to physics. Physics education with its emphasis on basic understanding is therefore going to play a larger rôle in other disciplines, including engineering. Moreover, the development of science and technology is based on the scientific knowledge accumulated throughout the whole world. This global pool can be efficiently explored only by capable scientists. Their duty is therefore not only to deepen our knowledge of Nature but to assist the innovator or product developer in using this global information. This process is best done through personal contacts.

\section{Stress New Activities and Cooperation}

How can the European Physical Society make a significant contribution to this evolution in the rôle of physics? In my opinion, the Society's basic structure is appropriate and no revolutionary changes are needed. The move towards a Society which can be more efficient in solving the problems of our time started a few years ago; but further develop-

$H$. Ferdinande (on the right) describing the European Mobility Scheme for Physics Students to R. Pike during EPS-9 in Florence last September. Professor Ferdinande is both a Regional Coordinator for the scheme and a Programme Coordinator handling contracts with the European Community.

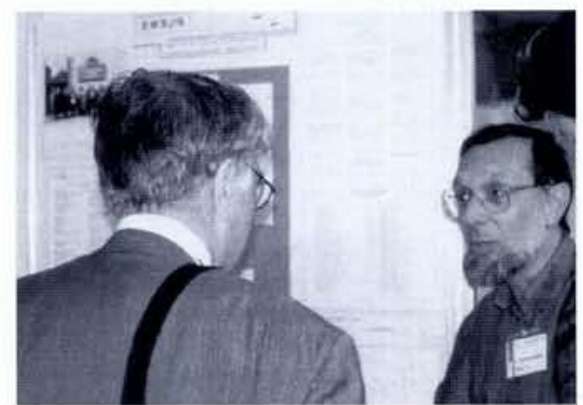

ment is required. Foremost is the need for the participation of a larger number of physicists. The formal solution to reach this goal is the new membership category (the so-called Full Member Societies) that we shall ask Council to approve at its meeting this March in Cracow. We hope that as a result of this change we shall have a more direct access to a larger number of colleagues.

EPS should also be a place where each member can take up some work, usefu for the community, in which he or she can realize certain goals. New activities have to be started if we are to expect a larger number of members to participate. This needs, of course, more finances. One of the most important new initiatives we are managing is the student mobility programme, launched in September 1993. More than 100 students are already participating, mostly from west European universities. Hopefully very soon the participation of students from east and central Europe can also be financed to a greater extent than is possible through programmes set up by the European Union.

Another activity of great importance is the integration of east and central European physics and physicists into all-European research activities. This was certainly one of the main objectives of our founding fathers and many efforts were undertaken, although not always with the hoped-for results. Following the fundamental changes to the political situation in east and central Europe we are confronted with new dimensions. We can in fact report on the results of some aid-type actions carried out by the Society. In the future, however, we have to concentrate much more on efforts to help build up cooperation which is useful for all participants and aims at equal opportunities for all concerned.

\section{Society Level Remains Vital}

The professional life of our Society is mostly concentrated in the Divisions where conferences, workshops, schools, and the like are the basis of the interaction between scientists. We must, and we intend to, pay more attention to Divisional activities since this is the basis of our long-term goal, namely to convert EPS into a truly European organization, fitting into the structure of a future, unified Europe. Moreover, the stronger involvement of the Divisions in the Society's general affairs will set off a natural rejuvenation, not only of the membership but also of governing bodies, since the younger generation is more strongly represented on Divisional boards.

These ideas, and some others I shall not mention, represent our means to strengthen 
EPS internally; they are mainly connected with the classical rôle of a learned society.

There are, however, tasks which can only be solved on a Society level as opposed to the Division level but are important for, and indeed characteristic of, a modern organization. Such tasks include, for example, the mobility programme mentioned above. The advisory rôle is another. International organizations prefer to ask for advice from bodies which do not have executive duties but possess a broad and large pool of knowledge. So it is perhaps not unexpected that the European Union, UNESCO, the European Science Foundation (ESF), the European Union of Physics Research Organizations (EUPRO), and other similar organizations are increasingly relying on our expertise.

Bridging the gap between research and industry is also one of our general tasks. The Action Committee for Applied Physics and Physics in Industry (ACAPPI) is a natural body in which to involve people from industry into our life. I would be glad if the number of active industrial members of EPS could be increased, with their greater participation in Council, Divisional boards and action committees. Physics teaching at the undergraduate level is the basis of general, mediumlevel science education while many graduate-level research and engineering professions are based on physics curricula. In order to integrate all levels of physics teachers into our Society we have recently organized an Interdivisional Group on Education to coordinate work in this important field.

Building up an interface between research and the general public is badly needed, both at the national and European levels, and we have to take up our share of this task. The Physics and Society Committee is an appropriate group to lead this activity. At the professional level, qualifications are playing an increasingly important rôle in physics, mainly in some applied areas. We shall ask Council in Cracow to decide upon the launch later this year of a proposed scheme.

Publication efforts have also to be implemented at the Society level. Europhysics News is a good bulletin with much useful information. My feeling is that science policy issues as seen from the Executive Committee should be published in it more frequently, and Divisions should be given greater encouragement to use it to inform the membership on their affairs. Europhysics Letters is a great success. I am glad to see a growing impact of this journal on European physics and an increasing number of high-quality papers, mainly in condensed matter physics. The EPS label on different European journals is prestigious and our Publications Committee keeps an eye on it to preserve scientific and editorial standards. The Europhysics Conference Abstracts series are of great value for obtaining the latest information on tendencies in particular fields of physics.

If EPS is strong internally we can pay more attention to, and be more self-confident in, strengthening our position on the European scene. This evolution is important because it leads not only to a possible increase in financial support from outside, but also to the Society being able to contribute more easily and efficiently to strengthening the position of physics research. But EPS is not the only physics-related society in Europe; contacts with other societies should be strengthened. We have formed a joint Division with the European Astronomical Society and have

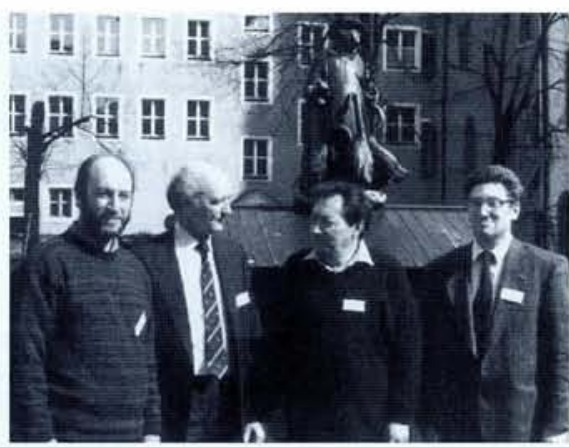

The President (second from the left) with three of the winners of the 1993 HewlettPackard Europhysics Prize. The photograph was taken during the 1993 General Conference of the Condensed Matter Division held in Regensberg with the German Physical Society's, Arbeitskreis Festkörperphysik. The 3777 participants meant it was the largest physics meeting ever held in Europe.

good relations with the European Materials Research Society; discussions with the European Optical Society have also started so as to improve relations.

Connections with the outside world are constantly improving. There are strong links with The American Physical Society which has Collaborating Society status, together with The Physical Society of Japan and The Japan Society of Applied Physics; the Asian Pacific Physical Society is also a partner. Last but not least, let me mention the Associate Members. These are companies, institutions, research institutes, and university chairs or institutes which give us significant financial and moral support; we have to find ways to make ourselves more useful to them. It is of course desirable that their number should increase.

The real European spirit of our Society is represented by the individual members. These are the people whose first question is not what they get from EPS but what they can do for European physics. It would be very satisfying to see their number increase and to be able to count upon their support in the future as the Society moves to involve members of national societies in the Divisions. Looking at the history of EPS as documented, for example, in the July/August 1993 issue of Europhysics News, we can be proud to see how much has been done by both our predecessors and ourselves in developing European physics. My experience is, however, that the more I am involved in EPS affairs the more problems I see which remain to be solved. The challenge is to do one's best to solve as large a fraction as possible of them by making use of the many opportunities that exist.

N. Kroó, KFKI, Budapest

\section{THE TREASURER REPORTS}

\section{Donations Allow More Activities}

The Society's Treasurer, Hans Beck from Neuchâtel, took over in March 1993 what was basically a sound ship thanks mainly to vigourous efforts by Philippe Choquard, the outgoing Treasurer, to stimulate income and to rein in costs. It had been proposed to the 1993 Council that the accumulated deficit would be reduced to essentially zero (SFR 5600 to be exact) and the provisional final result is SFR 6000 . The satisfactory outcome was achieved in spite of increasing the amount spent on targeted activities, where Council agreed to spend $17 \mathrm{kSFR}$. This was substantially more than the $10 \mathrm{kSFR}$ proposed for 1992, with the provisional final figures for 1992 - which will receive the Auditor's approval in a few days - showing $14.5 \mathrm{kSFR}$

The Treasurer, Hans Beck, speaking at the 1993 General Meeting of EPS members in Florence.

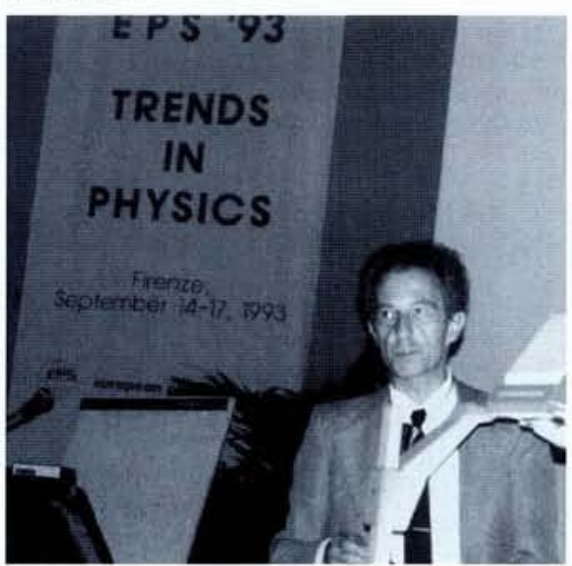

Important contributions from national societies to help cover the shortfall in membership income from societies in east and central Europe allowed this development of targeted activities. Some 12 kSFR was donated for sponsorships in 1992 and 24 kSFR in 1993 comprising 10 kSFR from The Institute of Physics, 9 kSFR from the German Physical Society, 3 kSFR from the Swiss Physical Society, and 1 kSFR from both the Swedish and Finnish societies.

\section{Few Surprises}

Turning to some of the details for 1993, the table shows that overall income was close to the 931 kSFR accepted by Council for the 1993 budget. Among the various items, the anticipated membership income was accurately estimated, income from Europhysics Letters was higher than anticipated and sponsorship of special issues of Europhysics News (a new item introduced in 1993) was not as high as was sought. On the expenditure side, apart from slightly higher Secretariat expenses, everything remained as expected.

The overall evolution of the Society's finances thus offers few surprises, with the figure showing how membership income has increased progressively since 1990 along with miscellaneous income and donations, while Europhysics News has been able to keep a relatively stable income. Regarding expenditure, salaries and expenses of the Secretariat dipped during the years the Executive Secretary was based in Budapest, and the increase in the costs attributed to Europhysics News was halted last year by reducing the number of issues published each year from 11 to 10 . The major problem was 